\title{
Inhibitory Effects of Herbal Extracts on the Activity of Human Sulfotransferase Isoform Sulfotransferase 1A3 (SULT1 A3)
}

\author{
Marie Nagai, ${ }^{a}$ Takahiro Fukamachi,${ }^{b}$ Masayuki Tsujimoto, ${ }^{b}$ Kenichiro Ogura, ${ }^{c}$ Akira Hiratsuka, ${ }^{c}$ \\ Hisakazu OHtani, ${ }^{a}$ Satoko Hori, ${ }^{a}$ and Yasufumi SAWADA $*, a, d$ \\ ${ }^{a}$ Laboratory of Drug Informatics, Graduate School of Pharmaceutical Sciences, The University of Tokyo; ${ }^{d}$ Graduate \\ School of Interdisciplinary Information Studies, The University of Tokyo; 7-3-1 Hongo, Bunkyo-ku, Tokyo 113-0033, \\ Japan: ${ }^{b}$ Department of Medico-Pharmaceutical Sciences, Graduate School of Pharmaceutical Sciences, Kyushu \\ University; 3-1-1 Maidashi, Higashi-ku, Fukuoka 812-8582, Japan: and 'c Department of Drug Metabolism and \\ Molecular Toxicology, School of Pharmacy, Tokyo University of Pharmacy and Life Science; 1432-1 Horinouchi, \\ Hachiouji, Tokyo 192-0392, Japan.
}

Received June 16, 2008; accepted October 20, 2008; published online October 23, 2008

Sulfotransferase 1A3 (SULT1A3) is a phase II detoxifying enzyme of xenobiotics predominantly expressed in the intestinal epithelium. Recent increase in the use of herbal extracts as dietary supplements may lead to an increase in the possibility of dietary supplement-drug interactions. The purpose of the present study was to investigate the effects of 18 herbal extracts on SULT1A3 activity and the possibility of interaction between medicinal drugs and herbal extracts. We examined the inhibitory potencies of 18 herbal extracts on the sulfation of dopamine, a typical substrate of SULT1A3, and ritodrine, a $\beta$, stimulant, by human recombinant SULT1A3. The sulfation of dopamine was inhibited by extracts of banaba, green tea, Rafuma, grape seed, peanut seed coat, gingko biloba leaf, St. John's wort, gymnema and milkthistle. The $\mathrm{IC}_{50}$ values of these herbal extracts were lower than the putative gastrointestinal concentration when the recommended dose was ingested. On the other hand, chlorella extract and rutin showed no inhibitory effects and wheat, mulberry and siberian ginseng had $\mathrm{IC}_{50}$ values exceedingly higher than the putative gastrointestinal concentration. The inhibitory profiles of herbal extracts for the sulfation of ritodrine were comparable to those for the sulfation of dopamine. In conclusion, the extracts of herbs such as banaba and green tea potently inhibited SULT1A3 activity. These extracts may increase the bioavailability of drugs whose bioavailabilities were limited by the function of SULT1A3 on the intestinal epithelium.

Key words herbal extract; sulfation; food-drug interaction; metabolic inhibition

Cytosolic sulfotransferases (SULTs) are a family of enzymes involved in the phase 2 detoxification of xenobiotics, including medicinal drugs such as ritodrine, salbutamol, minoxidil and paracetamol, ${ }^{1,2)}$ as well as in the sulfation of endogenous chemicals. ${ }^{3)}$ Thus, inhibition of SULT activity may affect drug pharmacokinetics which in turn could cause adverse reactions.

SULT1A3 and SULT1A1 are predominantly expressed in the intestinal epithelium and liver, respectively. ${ }^{4)}$ Therefore, food constituents that inhibit SULT1A3 may affect the absorption of drugs that undergo extensive presystemic sulfation, such as oral $\beta_{2}$ stimulants. We have previously encountered a case of adverse reaction associated with concomitant ingestion of grapefruit with the $\beta_{2}$ stimulant ritodrine, and demonstrated that several grapefruit constituents potently inhibit SULT1A3 and SULT1A1. ${ }^{1,5)}$ The intestinal and hepatic availabilities of ritodrine are estimated to be 0.68 and $0.54,{ }^{5)}$ respectively, suggesting that one-third of orally administered ritodrine is considered to be eliminated by intestinal first pass and another one-third by the liver. As $\beta_{2}$ stimulants including ritodrine are predominantly conjugated with sulfate in humans, ${ }^{6}$ ) SULTs are likely to play a key role in regulating the bioavailability of $\beta_{2}$ stimulants. Therefore, to avoid the above-mentioned interactions, it would be necessary to identify which foods inhibit SULT1A3 activity. However, there is little information about SULT1A3-mediated food-drug interactions, compared with the extensive studies of interactions mediated by other enzymes, such as cytochrome P450 (CYP) $3 \mathrm{~A} 4 .^{7,8)}$
Flavonoids potently inhibit SULT1A3..$^{5,9,10)}$ For example, we have reported that $10 \mu \mathrm{M}$ quercetin and $100 \mu \mathrm{M}$ catechin inhibit SULT1A3 activity by $50 \%$ and $70 \%$, respectively. ${ }^{5)}$ The intestinal SULT1A3 may be potently inhibited by the ingestion of foods containing the above compounds at high

Table 1. A List of Eighteen Herbal Extracts Investigated

\begin{tabular}{|c|c|c|}
\hline Test compounds & Scientific name of origin & Putative clinical use $\mathrm{e}^{21)}$ \\
\hline Banaba extract & Lagerstroemia speciosa & Blood glucose-lowering \\
\hline Green tea extract & Camellia sinensis & $\begin{array}{l}\text { Reducing cancer incidence, } \\
\text { lipid lowering etc. }\end{array}$ \\
\hline Rafuma extract & Apocynum venetum & \\
\hline Grape seed extract & Vitis vinifera & $\begin{array}{l}\text { Antioxidant and } \\
\text { cytoprotective effects }\end{array}$ \\
\hline Peanut seed coat extract & Arachis hypogaea & \\
\hline Ginko biloba leaf extract & Ginko biloba & $\begin{array}{l}\text { To treat dementias, cerebral } \\
\text { insufficiency anxiety/stress } \\
\text { etc. }\end{array}$ \\
\hline St. John's wort extract & Hypericum perforatum & Antidepressant \\
\hline Bilberry extract & Vaccinium myrtillus & Improving visual function \\
\hline Gymnema sylvestre extract & Gymnema sylvestre & Blood glucose-lowering \\
\hline Milkthistle extract & Silybum marianum & Liver protection \\
\hline Black cohosh extract & Cimicifuga racemosa & $\begin{array}{l}\text { Alleviation of menopause } \\
\text { symptom }\end{array}$ \\
\hline Soy bean extract & Glycine $\max$ & $\begin{array}{l}\text { Alleviation of menopause } \\
\text { symptom }\end{array}$ \\
\hline Passion flower extract & Passiflora incarnata & Sedative/anxiolytic \\
\hline Barley extract & Hordeum vulgare & Blood glucose/lipid-lowering \\
\hline Chlorella extract & Chlorella pyrenoidosa & \\
\hline Mulberry leaf extract & Morus alba & \\
\hline Siberian ginseng extract & Eleutherococcus senticosus & $\begin{array}{l}\text { Energy enhancement, } \\
\text { immunostimulant }\end{array}$ \\
\hline Rutin & Styphnolobium japonicum & \\
\hline
\end{tabular}


concentrations. Indeed, red wine, which contains quercetin at concentrations of up to $111 \mu \mathrm{M},{ }^{11)}$ was shown to inhibit SULT1A3 activity. ${ }^{12)}$ We have also shown that citrus juices and tea inhibit SULT activity, even after ten-fold dilution. ${ }^{1)}$

As the use of dietary supplements is becoming increasingly common, dietary supplement-drug interactions may become clinically significant. Dietary supplements often consist of herbal extracts, some of which are concentrated to give higher contents of herbal constituent(s). Although no report describes a case of drug interaction definitely attributable to the inhibition of intestinal SULT by dietary supplements, most dietary supplements and herbs are not contraindicated with $\beta_{2}$ stimulants including ritodrine, so that they can be casually taken together. The purpose of the present study was to investigate the effects of 18 herbal extracts (Table 1) on SULT1A3 activity and the likelihood of interaction between drugs and herbal extracts.

\section{MATERIALS AND METHODS}

Materials Unlabeled 3'-phosphoadenosine 5'-phosphosulfate (PAPS) was purchased from Sigma-Aldrich Co. (St. Louis, MO, U.S.A.). $\left[{ }^{35} \mathrm{~S}\right]$ PAPS $(3.0 \mathrm{Ci} / \mathrm{mmol})$ was purchased from PerkinElmer Life Sciences, Inc. (Boston, MA, U.S.A.). Eighteen herbal extracts (barley, chlorella, soy, passion fruit, mulberry leaf, siberian ginseng, rutin, green tea, Rafuma, grape seed, peanut seed coat, bilberry, banaba, St. John's wort, gingko leaf, milkthistle, black cohosh and gymnema) were kindly provided by Tokiwa Phytochemical Co., Ltd. (Chiba, Japan). Gymnema extract (94.2\%) was a gift from Phytotech Extracts Pvt. Ltd. (Bangalore, India) and contained $94.2 \%$ gymnemic acid. Hyperforin $(1 \mathrm{mg} / \mathrm{ml}$ in methanol) was purchased from Sequoia Research Products Ltd. (Oxford, U.K.). All other chemicals used were of analytical grade.

Preparation of Recombinant Human SULTs Escherichia coli expression plasmids for SULT1A3 was constructed as described previously. ${ }^{13)}$ Bacterial expression and purification of His-tagged recombinant human SULTs by one-step column chromatography were performed as described previously. ${ }^{14)}$ Fractions containing the homogenous enzyme protein, appearing as a single band on sodium dodecyl sulfate-polyacrylamide gel electrophoresis, were pooled as described previously. ${ }^{14)}$

Preparation of Inhibitor Solutions Herbal extracts were dissolved in incubation buffer $(50 \mathrm{~mm}$ sodium phosphate buffer containing $8 \mathrm{~mm}$ dithiothreitol and $3.75 \mathrm{~g} / \mathrm{l}(\mathrm{w} / \mathrm{v})$ BSA, $\mathrm{pH} 6.8$ ) to give a concentration of 10,100 or 1000 $\mu \mathrm{g} / \mathrm{ml}$. Soy extract, passion flower extract, mulberry extract, siberian ginseng extract, Rafuma extract, grape seed extract, peanut seed coat extract, banaba extract, St. John's wort extract, gingko leaf extract and milkthistle extract were dissolved in dimethylsulfoxide (DMSO) before being diluted with the incubation buffer to give a final DMSO concentration of $0.5 \%$. In this case, the buffer containing $0.5 \%$ DMSO was used as a control. Samples were filtered through a $0.20 \mu \mathrm{m}$ membrane filter (Millex-LG 25; Millipore Corp., Bedford, MA, U.S.A.) to eliminate insoluble materials. Hyperforin was dissolved in the incubation buffer to give final concentrations of 10,1 and $0.1 \mu \mathrm{g} / \mathrm{ml}$.

Enzyme Assay The inhibition study was performed by the method previously reported. ${ }^{15)}$ The reaction mixture, containing substrate, $\left[{ }^{35} \mathrm{~S}\right] 3^{\prime}$-phosphoadenosine $5^{\prime}$-phosphosulfate (PAPS) $(10 \mu \mathrm{M}, 100 \mathrm{mCi} / \mathrm{mmol})$, and enzyme $(18.75 \mathrm{ng})$ in $50 \mu \mathrm{l}$ of incubation buffer, was incubated for $10 \mathrm{~min}$ at $37^{\circ} \mathrm{C}$. The concentrations of the substrates were $5 \mu \mathrm{M}$ for dopamine and $100 \mu \mathrm{M}$ for ritodrine. After a 2-min preincubation, the reaction was initiated by the addition of the substrate together with herbal extract solutions, and terminated by placing the reaction vessel in an ice bath. An aliquot $(5 \mu \mathrm{l})$ of the reaction mixture was applied to a polyethyleneimine cellulose thin-layer plate (Macherey-Nagel $\mathrm{GmbH}$ \& Co., KG, Dueren, Germany) and developed with 1propanol: $30 \% \mathrm{NH}_{3}$ aq. : $\mathrm{H}_{2} \mathrm{O}(6: 3: 1(\mathrm{v} / \mathrm{v}))$. Radioactivity of the sulfate ester was determined by radioluminography with a bioimaging analyzer (BAS 1500, Fuji Photo Film, Tokyo, Japan).

Data Analysis Statistical significance was determined by one-way analysis of variance followed by Dunnett's test, and $p$ values of less than 0.05 (two-tailed) were considered statistically significant. The concentration of inhibitor giving half-maximal inhibition ( $\mathrm{IC}_{50}$ values) was determined by fitting Eq. 1 to the remaining enzyme activity in the presence of 10,100 and $100 \mu \mathrm{g} / \mathrm{ml}$ herbal extracts with nonlinear least-squares software (MLAB, Civilized Software Inc., Bethesda, MD, U.S.A.)

$$
Y=100-\frac{100 \times[\mathrm{I}]^{\gamma}}{\mathrm{IC}_{50}^{\gamma}+[\mathrm{I}]^{\gamma}}(\%)
$$

( $Y$ : SULT1A3 activity (\% of control), [I]: concentration of herbal extract, $\gamma$ : Hill's constant.)

The $\mathrm{IC}_{50}$ values larger than $1000 \mu \mathrm{g} / \mathrm{ml}$ are presented as $>1000 \mu \mathrm{g} / \mathrm{ml}$. The rank correlation of $\mathrm{IC}_{50}$ values of dopamine sulfation and those of ritodrine sulfation was also determined.

To estimate the clinical significance of SULT inhibition by herbal extracts, the concentration of inhibitor at the site of inhibition should be taken into account. As sulfotransferase is expressed in 118 the cytosol of intestinal epithelial cells, we assumed that the enzyme is exposed to the inhibitor with 119 a concentration similar to that in the intestinal fluid. Therefore, we introduced an index, inhibition ratio (I.R.), as defined by Eq. 2 .

$$
\text { I.R. }=\frac{\text { recommended daily intake }(\mathrm{mg})}{\text { volume of gastrointestinal fluid }(1) \times \mathrm{IC}_{50}(\mu \mathrm{g} / \mathrm{ml})}
$$

The recommended daily intake of each extract was taken from the Physicians' Desk Reference (PDR) for Herbal Medicines $^{16)}$ or the manufacturers' instructions for dietary supplements in Japan. The volume of gastrointestinal fluid was assumed to be 11 .

\section{RESULTS}

Eleven extracts, i.e., banaba, green tea, Rafuma, grape seed, peanut seed coat, gingko, St. John's wort, gymnema, bilberry, milkthistle and black cohosh, inhibited the sulfation of dopamine by SULT1A3 in a concentration-dependent manner. Banaba extract, green tea extract, Rafuma extract, grape seed extract and peanut seed coat completely inhibited SULT1A3 activity at a concentration of $1000 \mu \mathrm{g} / \mathrm{ml}$. Banaba extract and green tea extract exhibited the most potent inhibi- 
tion, with $\mathrm{IC}_{50}$ values of $16.0 \mu \mathrm{g} / \mathrm{ml}$ and $22.0 \mu \mathrm{g} / \mathrm{ml}$, respectively (Table 2).

Banaba extract, green tea extract, Rafuma extract, gingko leaf extract, grape seed extract and St. John's wort extract markedly inhibited the sulfation of ritodrine, a $\beta_{2}$ adrenoceptor agonist, by SULT1A3 at a concentration of $1000 \mu \mathrm{g} / \mathrm{ml}$. The lowest $\mathrm{IC}_{50}$ value was given by green tea extract $\left(\mathrm{IC}_{50}=6.67 \mu \mathrm{g} / \mathrm{ml}\right)$ followed by banaba extract $\left(\mathrm{IC}_{50}=7.49\right.$ $\mu \mathrm{g} / \mathrm{ml}$ ) (Table 3). Rafuma, grape seed, peanut seed coat, gingko, St. John's wort, bilberry and milkthistle extracts significantly inhibited SULT1A3 activity in a concentration-dependent manner.

A significant correlation was observed between the $\mathrm{IC}_{50}$ values for dopamine sulfation and those for ritodrine sulfation $(r=0.813, p<0.001)$. The $\mathrm{IC}_{50}$ values for dopamine sul- fation tended to be lower than those for ritodrine sulfation.

The composition of each herbal extract varies from product to product, even among those prepared from the same raw material. Gymnema and St. John's wort extract were chosen to investigate the effect of the composition of the extract on the inhibitory activity of SULT1A3.

The inhibitory effects of two gymnema extract products, containing gymnemic acid at concentrations of $10.6 \%$ and $94.2 \%$, were investigated. The former extract $(10.6 \%)$ inhibited the sulfation of dopamine by $88 \%$ and $27.3 \%$ at the concentrations of $1000 \mu \mathrm{g} / \mathrm{ml}$ and $100 \mu \mathrm{g} / \mathrm{ml}$, respectively (Table $3)$. On the other hand, the latter $(94.6 \%)$ inhibited the sulfation of dopamine by $97.6 \%, 28.1 \%$ and $36.4 \%$ at the concentrations of $1000 \mu \mathrm{g} / \mathrm{ml}, 100 \mu \mathrm{g} / \mathrm{ml}$ and $10 \mu \mathrm{g} / \mathrm{ml}$, respectively.

St. John's wort products contained more or less the same

Table 2. Inhibitory Potencies of Various Herbal Extracts on the Sulfation of Dopamine by SULT1A3

\begin{tabular}{|c|c|c|c|c|c|c|}
\hline & \multirow{2}{*}{$\begin{array}{l}\left.\text { Recommended }{ }^{a}\right) \\
\text { daily intake }(\mathrm{mg})\end{array}$} & \multicolumn{3}{|c|}{ Dopamine ( $\%$ of control) } & \multirow{2}{*}{$\mathrm{IC}_{50}(\mu \mathrm{g} / \mathrm{ml})$} & \multirow{2}{*}{ Inhibition ratio ${ }^{c)}$} \\
\hline & & $10 \mu \mathrm{g} / \mathrm{ml}$ & $100 \mu \mathrm{g} / \mathrm{ml}$ & $1000 \mu \mathrm{g} / \mathrm{ml}$ & & \\
\hline Banaba extract & $80^{b)}$ & 72.5 & $2.29 * *$ & $0 * *$ & 16.0 & 5.00 \\
\hline Green tea extract & $400^{b)}$ & 90.9 & $4.67 * *$ & $0 * *$ & 22.0 & 18.2 \\
\hline Rafuma extract & $60^{b)}$ & 94.4 & $15.4^{* *}$ & $0 * *$ & 42.0 & 1.43 \\
\hline Grape seed extract & 100 & 98.0 & $10.3 * *$ & $0 * *$ & 43.9 & 2.28 \\
\hline Peanut seed coat extract & $250^{b)}$ & 94.4 & $10.7^{* *}$ & $0 * *$ & 62.7 & 3.99 \\
\hline Ginko biloba leaf extract & 120 & 99.6 & $44.2 * *$ & $3.46 * *$ & 88.3 & 1.36 \\
\hline St. John's wort extract & 300 & 89.8 & $56.5^{* *}$ & $0.130 * *$ & 114 & 2.63 \\
\hline Bilberry extract & 120 & 105 & $71.0^{* *}$ & $5.45 * *$ & 170 & 0.71 \\
\hline Gymnema sylvestre extract & $700^{b)}$ & 86.8 & $72.7 *$ & $12.0 * *$ & 203 & 3.45 \\
\hline Milkthistle extract & 300 & 97.9 & $75.4 * *$ & $13.1 * *$ & 236 & 1.27 \\
\hline Black cohosh extract & 40 & 91.7 & $75.7 * *$ & $17.8 * *$ & 262 & 0.15 \\
\hline Soy bean extract & 160 & 102 & 96.9 & $47.7 * *$ & $>1000$ & $<0.16$ \\
\hline Passion flower extract & $100^{b)}$ & 99.4 & 103 & $46{ }^{* *}$ & $>1000$ & $<0.1$ \\
\hline Barley extract & $50^{b)}$ & 87.0 & 87.0 & $74.1^{*}$ & $>1000$ & $<0.05$ \\
\hline Chlorella extract & $4000^{b)}$ & 104 & 93.8 & 82.8 & $>1000$ & $<4$ \\
\hline Mulberry leaf extract & $500^{b)}$ & $77.7 *$ & 86.3 & $55.0 * *$ & $>1000$ & $<0.5$ \\
\hline Siberian ginseng extract & $100^{b)}$ & 94.6 & 91.7 & $75.0 * *$ & $>1000$ & $<0.1$ \\
\hline Rutin & $500^{b)}$ & 98.6 & 101 & 94.7 & $>1000$ & $<0.5$ \\
\hline
\end{tabular}

a) PDR $[b)$ those without recommendation in PDR; in these cases the dose was that recommended on the package]. $c$ ) Inhibition ratio=recommended daily intake/gastrointestinal fluid volume/ $/ \mathrm{IC}_{50} * p<0.05, * * p<0.01 v s$. control.

Table 3. Inhibitory Potencies of Various Herbal Extracts on the Sulfation of Ritodrine by SULT1A3

\begin{tabular}{|c|c|c|c|c|c|c|}
\hline & \multirow{2}{*}{$\begin{array}{l}\text { Recommended }^{a)} \\
\text { daily intake }(\mathrm{mg})\end{array}$} & \multicolumn{3}{|c|}{ Ritodrine ( $\%$ of control) } & \multirow{2}{*}{$\mathrm{IC}_{50}(\mu \mathrm{g} / \mathrm{ml})$} & \multirow{2}{*}{ Inhibition ratio ${ }^{c}$} \\
\hline & & $10 \mu \mathrm{g} / \mathrm{ml}$ & $100 \mu \mathrm{g} / \mathrm{ml}$ & $1000 \mu \mathrm{g} / \mathrm{ml}$ & & \\
\hline Banaba extract & $80^{b)}$ & $43.5 * *$ & $4.21 * *$ & $2.48 * *$ & 7.49 & 10.7 \\
\hline Green tea extract & $400^{b)}$ & $42.0 * *$ & $-1.59 * *$ & $-0.900 * *$ & 6.67 & 60.0 \\
\hline Rafuma extract & $60^{b)}$ & 99.0 & $47.9^{* *}$ & $1.59 * *$ & 94.8 & 0.633 \\
\hline Grape seed extract & 100 & $59.4 * *$ & $37.6^{* *}$ & $2.18 * *$ & 24.3 & 4.12 \\
\hline Peanut seed coat extract & $250^{b)}$ & $58.0 * *$ & $50.4 * *$ & $19.4^{* *}$ & 41.4 & 6.04 \\
\hline Ginko biloba leaf extract & 120 & $53.3 * *$ & $19.7 * *$ & $2.01 * *$ & 12.3 & 9.76 \\
\hline St. John's wort extract & 300 & $76.5 * *$ & $62.3 * *$ & $2.11 * *$ & 98.0 & 3.06 \\
\hline Bilberry extract & 120 & 87.7 & $51.0 * *$ & $-0.90 * *$ & 90.0 & 1.33 \\
\hline Gymnema sylvestre extract & $700^{b)}$ & 90.9 & 73.7 & $4.35 * *$ & 193 & 3.63 \\
\hline Milkthistle extract & 300 & 110 & $47.4 * *$ & $22.3 * *$ & 129 & 2.33 \\
\hline Black cohosh extract & 40 & $54.5^{* *}$ & $41.9^{* *}$ & $2.40 * *$ & 21.0 & 1.90 \\
\hline Soy bean extract & 160 & $66.5 * *$ & $57.7 * *$ & $22.0 * *$ & 93.7 & 1.71 \\
\hline Passion flower extract & $100^{b)}$ & $62.5 * *$ & $55.2 * *$ & $25.4 * *$ & 78.1 & 1.28 \\
\hline Barley extract & $50^{b)}$ & 101 & 97.5 & 89.3 & $>1000$ & $<0.05$ \\
\hline Chlorella extract & $4000^{b)}$ & 98.8 & 106 & 82.2 & $>1000$ & $<4$ \\
\hline Mulberry leaf extract & $500^{b)}$ & 106 & 92.2 & $51.5 * *$ & $>1000$ & $<0.5$ \\
\hline Siberian ginseng extract & $100^{b)}$ & $74.0 * *$ & $72.9 * *$ & $60.4 * *$ & $>1000$ & $<0.1$ \\
\hline Rutin & $500^{b)}$ & 93.3 & 99.7 & 97.4 & $>1000$ & $<0.5$ \\
\hline
\end{tabular}

a) PDR $[b$ ) those without recommendation in PDR; in these cases, the dose was that recommended on the package]. $c$ ) Inhibition ratio $=$ recommended daily intake/gastrointestinal fluid volume $/ \mathrm{IC}_{50} * p<0.05, * * p<0.01 v s$. control. 
concentration $(1.3-4.0 \%)$ of the pharmacological active ingredient, hyperforin. Therefore, the inhibitory effect of authentic hyperforin on SULT1A3 activity was examined. While the $\mathrm{IC}_{50}$ value of St. John's wort was $114 \mu \mathrm{g} / \mathrm{ml}$ for dopamine sulfation (Table 3), hyperforin at concentrations up to $10 \mu \mathrm{g} / \mathrm{ml}$ did not significantly inhibit the activity of SULT1A3.

\section{DISCUSSION}

Most herbal extracts tested were shown to inhibit the sulfation of dopamine and that of ritodrine by SULT1A3 with comparable potencies. Thus, there seems to be a possibility of clinically significant food-drug interactions via the inhibition of intestinal SULT1A3.

Among the extracts tested, green tea and banaba extracts showed the most potent SULT1A3-inhibitory activity. The green tea extract $\left(\mathrm{IC}_{50}=22.0 \mu \mathrm{g} / \mathrm{ml}\right)$ used in this study contains polyphenols $(94.0 \%)$, particularly $(-)$-epigallocatechin galate, which comprises $44.3 \%$ of the extract. (-)-Epigallocatechin galate potently inhibits SULT1A3 activity with the $\mathrm{IC}_{50}$ value of $22.0 \mu \mathrm{g} / \mathrm{ml}^{5}{ }^{5}$ Other major constituents of the green tea extracts, catechin and epigallocatechin, also potently inhibit SULT1A3 with $\mathrm{IC}_{50}$ values of 8.3 and $14.6 \mu \mathrm{g} / \mathrm{ml}$, respectively. ${ }^{5)}$ Taken together, the inhibitory effects of green tea extract may be primarily attributable to these catechins. Banaba extract also contains $9-12 \%$ polyphenols, ${ }^{17}$ ) and most polyphenols inhibit SULT activity. ${ }^{18)}$ Therefore, the inhibitory activity of banaba could be attributable to these polyphenols. However, further studies using candidate substances will be needed to identify the actual constituent(s) responsible for SULT inhibition.

To quantitatively estimate the likelihood of food-drug interaction via the inhibition of intestinal SULT, we introduced an index, I.R., defined as the quotient of putative concentration in the gastrointestinal tract by the $\mathrm{IC}_{50}$ value. Of the 11 herbal extracts that inhibited sulfation of dopamine, all but bilberry and black cohosh extract gave I.R. values larger than unity, suggesting that food-drug interaction involving these extracts are likely. Green tea extract has the largest I.R. value among the extracts investigated, suggesting the possibility to cause drug interaction by inhibiting SULT1A3, while no report describes a case of interaction definitely attributable to the inhibition of intestinal SULT1A3 until now. Further clinical studies or case reports are needed to clarify the clinical significance of the inhibition of intestinal SULT1A3. A high I.R. value was not always accompanied with a low $\mathrm{IC}_{50}$ value; e.g., Rafuma has a smaller $\mathrm{IC}_{50}$ value than gymnema $(42.0 \mu \mathrm{g} / \mathrm{ml} v s .203 \mu \mathrm{g} / \mathrm{ml})$, but its I.R. value is three-fold lower (1.43vs. 3.45). On the other hand, extracts without inhibitory effects, such as chlorella and rutin, and those with I.R. values far below unity, such as wheat, mulberry and siberian ginseng, are unlikely to cause food-drug interactions. There are some limitations in estimating is the extent of drug interactions by using I.R. values. First, the accuracy of the $\mathrm{IC}_{50}$ values in this study is limited because they were estimated from the inhibitory potencies of three concentration levels $(10,100,1000 \mu \mathrm{g} / \mathrm{ml})$. Second, the concentration of an inhibitor in the gastrointestinal tract is assumed to be equivalent to that in the cytosol of intestinal epithelial cells, where SULT exists. This assumption may lead to an overesti- mation of the extent of interaction for hydrophilic inhibitors with low membrane permeability.

Similarly, the sulfation of ritodrine by SULT1A3 was inhibited by herbal extracts with comparable potencies to those found with dopamine. These results are in good accordance with our previous findings that green tea, oolong tea and black tea infusions exhibited similar inhibitory profiles on the SULT1A3-mediated sulfation of five substrates. ${ }^{1)}$ The results indicate that the inhibitory potency of a food can be predicted by evaluating its inhibition of SULT1A3 activity towards dopamine as a substrate.

The composition of extracts, even from the same herb, may vary depending on the manufacturer, harvesting season and other factors. We tested two gymnema extract products containing $94.2 \%$ and $10.6 \%$ gymnemic acid, and found that both inhibited SULT1A3 in a concentration-dependent manner with similar potency. Therefore, the inhibition of SULT1A3 by gymnema extract is attributable not to gymnemic acid, but to other constituents, possibly flavonoids, which are abundant in gymnema. ${ }^{19)}$ St. John's wort extract also inhibited SULT1A3 at the concentration of $100 \mu \mathrm{g} / \mathrm{ml}$, while its putative pharmacologically active constituent, hyperforin, did not show any inhibitory effect at concentration of up to $10 \mu \mathrm{g} / \mathrm{ml}$. If the St. John's wort extract used in the study contained $2-3 \mu \mathrm{g} / \mathrm{ml}$ hyperforin (St. John's wort extract commonly contains $1.3-4.0 \%$ hyperforin ${ }^{20)}$ ), then hyperforin is not responsible for the inhibitory effects of St. John's wort. St. John's wort extract contains flavonoids such as quercetin, whose $\mathrm{IC}_{50}$ value for the sulfation of dopamine was reported to be $9 \mu \mathrm{g} / \mathrm{ml},{ }^{18)}$ at a concentration of $4.8-11.4 \%{ }^{20)}$ Flavonoids may therefore also be responsible for the inhibition of SULT1A3 by St. John's wort.

We did not carry out the animal study to investigate whether these herbal extracts exert drug interactions by inhibiting SULT activity, because, in rat or rabbit intestine, $\beta_{2}$ stimulants including ritodrine predominantly undergo glucuronide conjugation but not sulfate conjugation. ${ }^{6}$

In conclusion, among the 18 herbal extracts tested, eleven inhibited SULT1A3-mediated dopamine sulfation. Banaba, green tea, Rafuma, grape seed, peanut seed coat, gingko biloba leaf, St. John's wort, gymnema and milkthistle extracts were considered likely to inhibit intestinal SULT1A3 after ingestion at the recommended dose, and banaba and green tea extracts were estimated to show the most potent inhibition. The inhibitory activities of herbal extracts on the sulfation of ritodrine were comparable to those in the case of dopamine. Thus these extracts may increase the bioavailability of drugs for which the function of SULT1A3 at the intestinal epithelium is bioavailability-limiting.

Acknowledgments This research was supported in parts by the Mochida Memorial Foundation for Medical and Pharmaceutical Research, and Foundation for Total Health Promotion. We thank Tokiwa Phytochemical Co., Ltd. (Chiba, Japan) for their generous gift of herbal extracts and Phytotech Extracts Pvt. Ltd. (Bangalore, India) for the kind gift of a sample of gymnema extract $(92.4 \%)$.

\section{REFERENCES}

1) Nishimuta H., Tsujimoto M., Ogura K., Hiratsuka A., Ohtani H., 
Sawada Y., Pharm. Res., 22, 1406-1410 (2005).

2) Eaton E. A., Walle U. K., Wilson H. M., Aberg G., Walle T., Br. J. Clin. Pharmacol., 41, 201-206 (1996).

3) Coughtrie M. W., Pharmacogenomics J., 2, 297-308 (2002).

4) Cappiello M., Giuliani L., Pacifici G. M., Pharmacology, 40, 69-76 (1990).

5) Nishimuta H., Ohtani H., Tsujimoto M., Ogura K., Hiratsuka A., Sawada Y., Biopharm. Drug Dispos., 28, 491-500 (2007).

6) Koster A. S., Frankhuijzen-Sierevogel A. C., Noordhoek J., Drug Metab. Dispos., 13, 232-238 (1985).

7) Tsunoda S. M., Harris R. Z., Christians U., Velez R. L., Freeman R. B., Benet L. Z., Warshaw A., Clin. Pharmacol. Ther., 70, 462-467 (2001).

8) Markowitz J. S., Donovan J. L., DeVane C. L., Taylor R. M., Ruan Y., Wang J. S., Chavin K. D., JAMA, 290, 1500-1504 (2003).

9) Ghazali R. A., Waring R. H., Life Sci., 65, 1625-1632 (1999).

10) Coughtrie M. W., Johnston L. E., Drug Metab. Dispos., 29, 522-528 (2001).

11) USDA Database for the Flavonoid Content of Selected Foods., U.S Department of Agriculture, 2003, http://www.nal.usda.gov/fnic/foodcomp/Data/Flav/flav.pdf.

12) Gibb C., Glover V., Sandler M., Biochem. Pharmacol., 36, 23252330 (1987).
13) Nishiyama T., Ogura K., Nakano H., Kaku T., Takahashi E., Ohkubo Y., Sekine K., Hiratsuka A., Kadota S., Watabe T., Drug Metab. Pharmacokinet., 17, 221-228 (2002).

14) Nakano H., Ogura K., Takahashi E., Harada T., Nishiyama T., Muro K., Hiratsuka A., Kadota S., Watabe T., Drug Metab. Pharmacokinet., 19, 216-226 (2004).

15) Sekura R. D., Marcus C. J., Lyon E. S., Jakoby W. B., Anal. Biochem., 95, 82-86 (1979).

16) "Physicians' Desk Reference for Herbal Medicines," 2nd ed., ed. by Gruenwald J., Brender B. A., Jaenicke C., Medical Economics Company, Inc., Montavale, NJ, 2000

17) Hosoyama H., Sugimoto A., Suzuki Y., Sakane I., Kakuda T., Yakugaku Zasshi, 123, 599-605 (2003).

18) Harris R. M., Wood D. M., Bottomley L., Blagg S., Owen K., Hughes P. J., Waring R. H., Kirk C. J., J. Clin. Endocrinol. Metab., 89, 17791787 (2004).

19) Liu X., Ye W., Yu B., Zhao S., Wu H., Che C., Carbohydr. Res., 339 $891-985$ (2004).

20) von Eggelkraut-Gottanka S. G., Abu Abed S., Muller W., Schmidt P C., Phytochem. Anal., 13, 170-176 (2002).

21) "The Review of Natural Products," 4 th ed., ed. by DerMarderosian A., Beutler J. A., Wolters Kluwer Health, Inc., PA, 2005. 